\title{
The relevance of mid-Holocene Arctic warming to the future
}

\section{(Supplementary figures)}

\author{
Masakazu Yoshimori ${ }^{1,2 *}$ and Marina Suzuki ${ }^{3}$ \\ ${ }^{1}$ Faculty of Environmental Earth Science, Global Institution for Collaborative Research \\ and Education, and Arctic Research Center, \\ Hokkaido University, Sapporo, Japan \\ ${ }^{2}$ Atmosphere and Ocean Research Institute, The University of Tokyo, Kashiwa, Japan \\ ${ }^{3}$ Graduate School of Environmental Science, Hokkaido University, Sapporo, Japan
}

Manuscript is to be submitted to Climate of the Past (12 December 2018)

* Corresponding author address: Atmosphere and Ocean Research Institute, The University of Tokyo, 5-1-5, Kashiwanoha, Kashiwa, Chiba 277-8568 Japan

Phone:+81-4-7136-4380, Fax:+81-4-7136-4375, E-mail: masakazu@aori.u-tokyo.ac.jp 


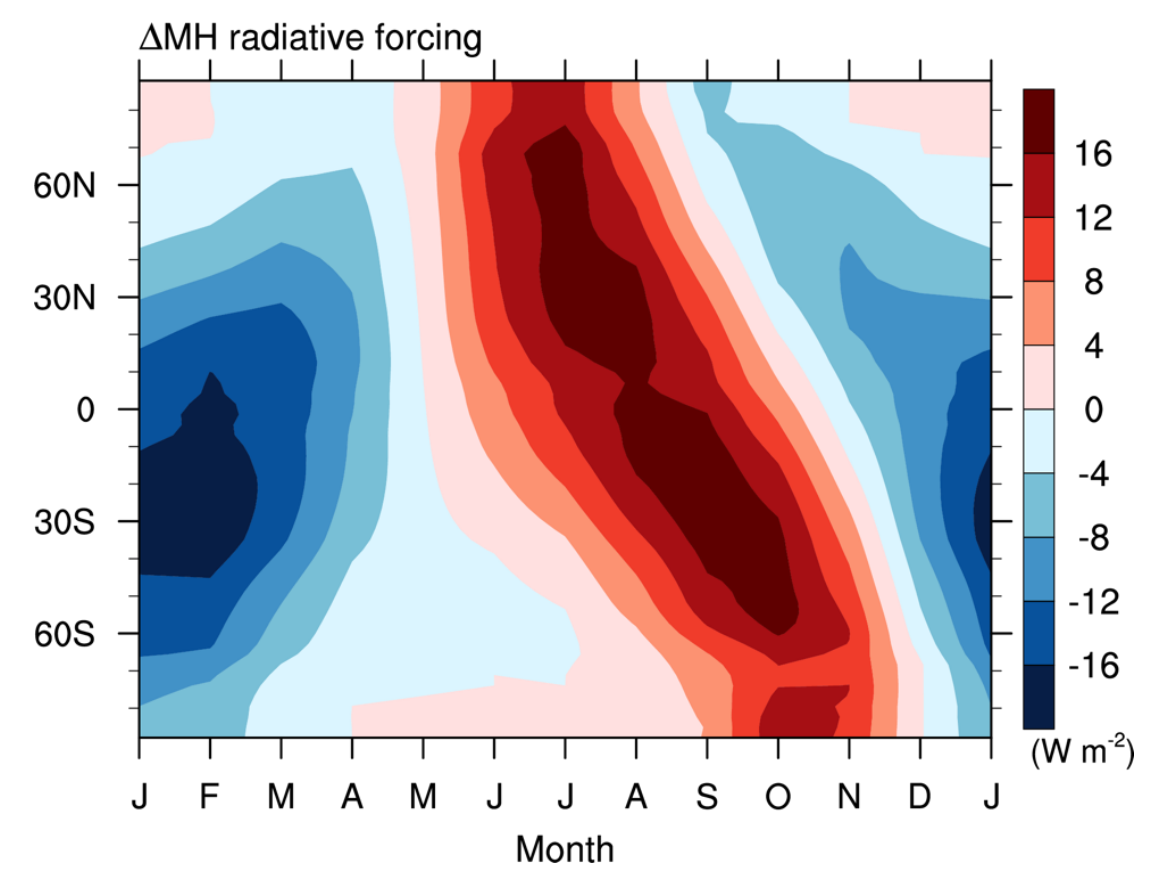

2

3 Fig. S1 Seasonal progress of the zonal mean radiative forcing calculated with the 4 insolation anomaly for $\Delta \mathrm{MH}$ and planetary albedo from the PI experiment $\left(\mathrm{W} \mathrm{m}^{-2}\right)$. The 5 mean of all 10 models was used. See main text for details. 
(a) Annual (proxy)

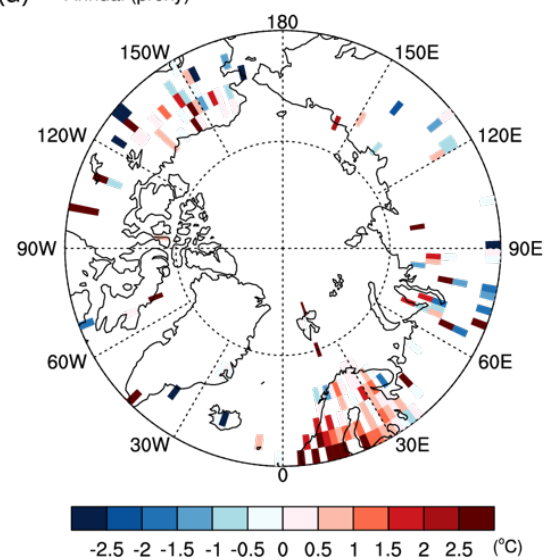

(C) Warmest month (proxy)
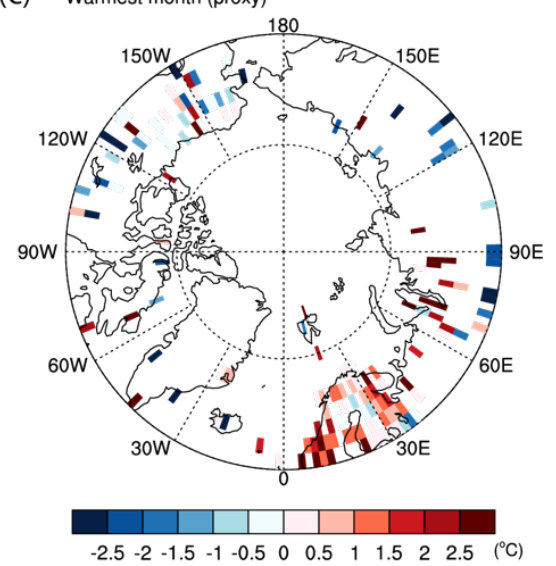

(e) Coldest month (proxy)

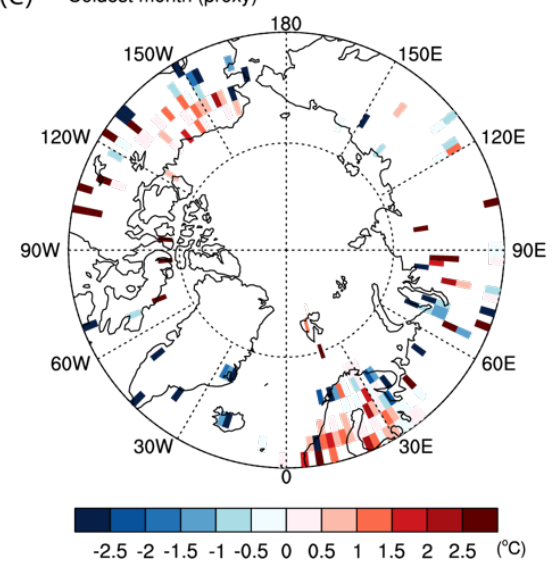

(b) Annual (model)

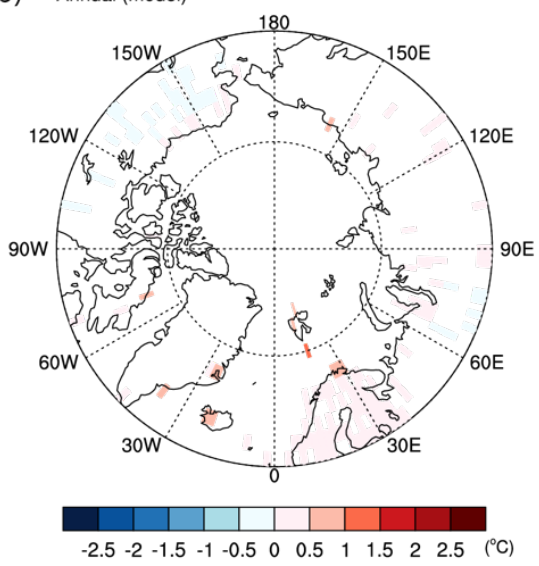

(d) Warmest month (model)

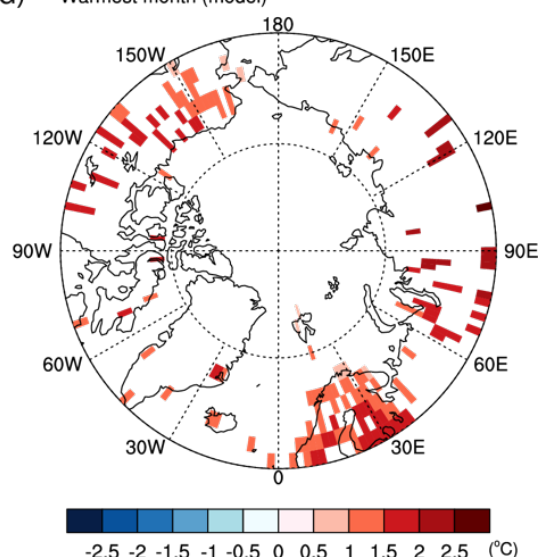

(f) Coldest month (model)

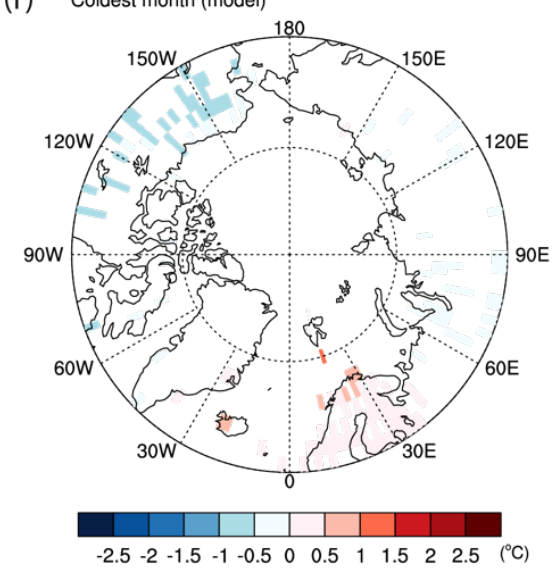

Fig. S2 Surface air temperature anomaly $\left({ }^{\circ} \mathrm{C}\right)$ for $\Delta \mathrm{MH}$ from the reconstruction (left) and simulations (right): (a) \& (b) annual mean, (c) \& (d) warmest month, and (e) \& (f) coldest month. The reconstruction data are taken from the extended data of Bartlein et al. (2011). The mean of all 10 model simulations was used. 

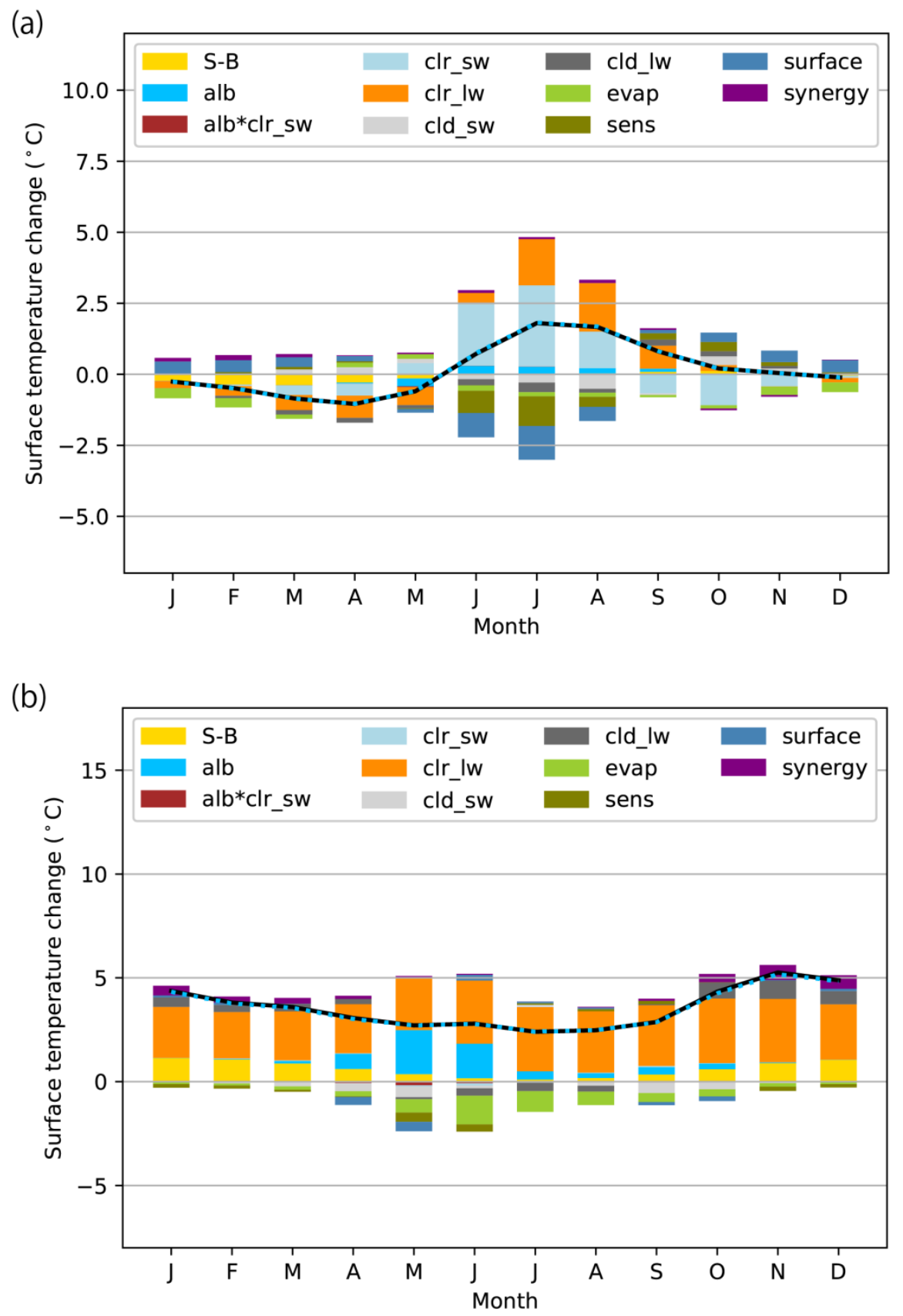

16 Figure S3 Simulated and diagnosed surface temperature changes $\left({ }^{\circ} \mathrm{C}\right)$ for the land (north of $1760^{\circ} \mathrm{N}$ ): (a) $\triangle \mathrm{MH}$; and (b) $\triangle \mathrm{RCP} 4.5$. The black lines denote simulated changes and blue dashed 18 lines denote the sum of diagnosed partial changes. The graphs represent the means of all 10 models. See Table 3 for the interpretation of each component. 
(a)

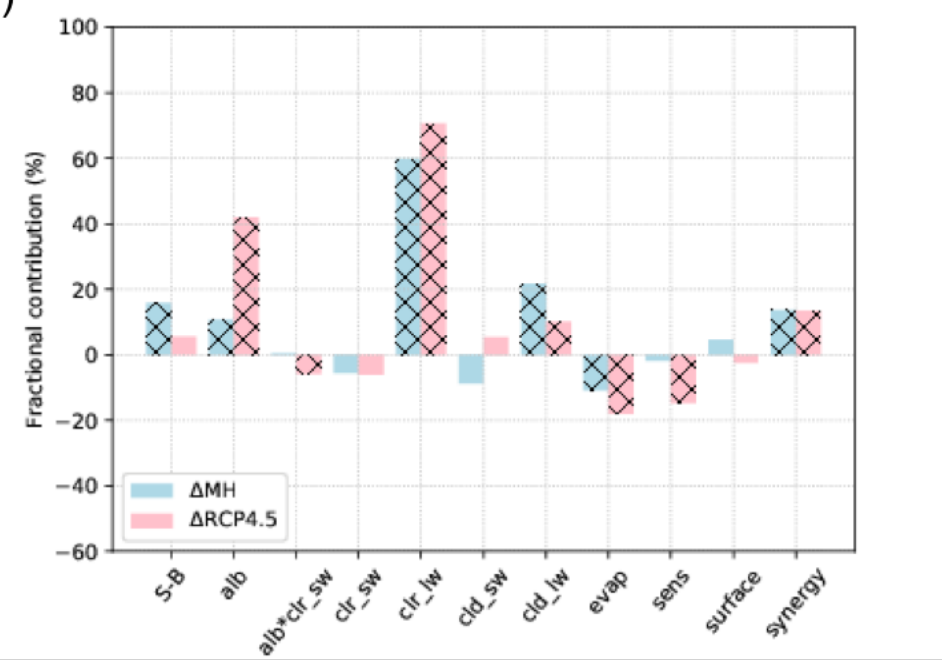

(b)

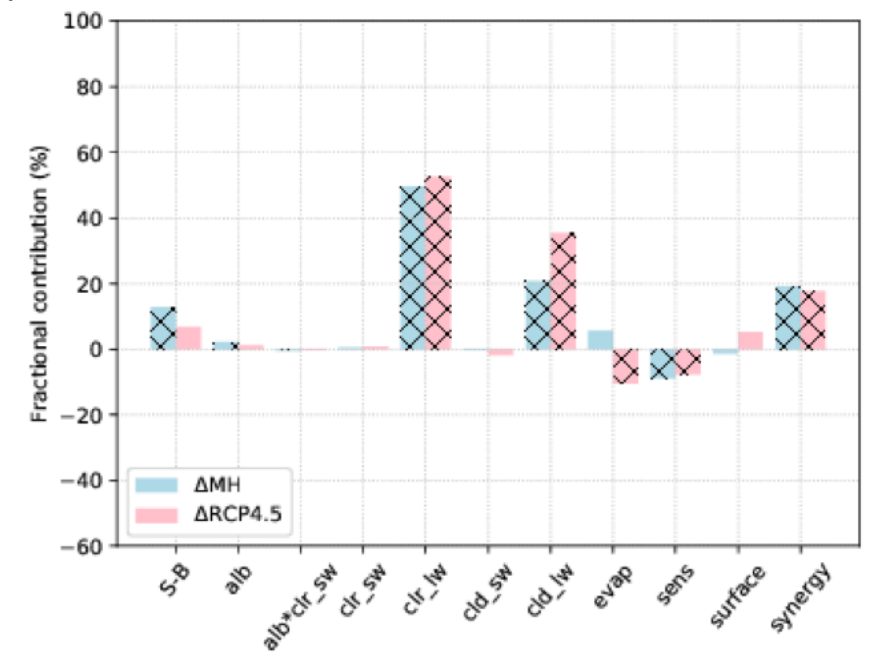

Figure S4 Fractional contribution of individual processes to the simulated surface temperature change (\%) over the land (north of $60^{\circ} \mathrm{N}$ ) for $\triangle \mathrm{MH}$ and $\triangle \mathrm{RCP} 4.5$ : (a) annual mean; (b) October-November-December mean. The sum of the bar graphs in the same color for each plot adds up to $100 \%$. The hatching indicates the contribution is statistically significant at the 


\section{Reference}

30 Bartlein, P. J., and Coauthors: Pollen-based continental climate reconstructions at 6 and 21 31 a global synthesis.

Climate

Dynamics,

37, $\quad$ 775-802.DOI 10.1007/s00382-010-0904-1, 2011

33 